\title{
Investigation of Formaldehyde Content in Dairy Products Available in Bangladesh by a Validated High Performance Liquid Chromatographic Method
}

\author{
Md. Shahadat Hossain, Md. Samiul Islam, Subrata Bhadra and \\ Abu Shara Shamsur Rouf
}

Department of Pharmaceutical Technology, Faculty of Pharmacy, University of Dhaka, Dhaka-1000, Bangladesh

(Received: June 01, 2016; Accepted: October 30, 2016; Published (web): December 27, 2016)

\begin{abstract}
Highly nutritious dairy products are ingested regularly by all ages of population. Adulteration of dairy products to enhance the inherent stability and acceptability to common consumers by different harmful and toxic ingredients like formalin, an unpermitted preservative, has been a burning issue in Bangladesh over the last few years. The aim of this paper was to analyze the concentration of formaldehyde in dairy products most commonly sold in Bangladeshi markets by a validated reversed phase high performance liquid chromatographic (RP-HPLC) method to reveal the on-going alarming scenario in a scientific way. After pre-derivatization with 2,4dinitrophenylhydrazine, formaldehyde was detected at $345 \mathrm{~nm}$ using a $\mathrm{C}_{18}$ column with acetonitrile and water (45:55) as mobile phase at a flow rate of $2.0 \mathrm{ml} / \mathrm{min}$. The validated method has been applied to 41 marketed dairy products, including pasteurized milk, UHT milk, banana- mango- and chocolate-milk, flavored yoghurt, lassi, buttermilk, and skimmed milk. However, no formaldehyde was detected among the tested dairy products.
\end{abstract}

Key words: HPLC, formaldehyde, dairy products, Bangladesh

\section{INTRODUCTION}

Dairy products in our diet supplies nutrients like proteins, fat, carbohydrates, vitamins and minerals in significant amount than any other single foods. ${ }^{1}$ As a perishable food, milk is highly susceptible to microbes like psychrotrophic bacteria, coliforms, lactic acid bacteria, as well as yeasts and molds. ${ }^{2}$ These microorganisms can deteriorate the quality of milk if milking is carried out under unhygienic conditions. The other sources that may affect the quality of milk are transportation vehicle and poor storage conditions which result in poor quality of milk in terms of its composition and bacterial quality. ${ }^{1} \quad$ Listeria monocytogenes is frequently associated with food borne disease outbreaks that are characterized by widespread distribution and relatively high mortality rates. ${ }^{3}$ Many effective and

Correspondence to: Abu Shara Shamsur Rouf

E-mail:rouf321@yahoo.com

Dhaka Univ. J. Pharm. Sci. 15(2): 187-194, 2016 (December) safe measures like pasteurization, ultra-high temperature treatments can be taken to avoid the deterioration of the milk products. But, in different regions of Bangladesh, various harmful preservatives are being frequently used to increase the shelf life of milk products. ${ }^{4}$ Moreover, adulteration of milk is also done to increase its volume and then starch and other reconstituted milk powders are added to increase its viscosity. ${ }^{1}$

Researchers have reported that artificial preservatives such as nitrates, benzoates, sulfites, sorbates, parabens, formaldehyde, BHT, BHA and several others can cause serious health hazards such as hypersensitivity, allergy, asthma, hyperactivity, neurological damage and cancer. ${ }^{5}$ Among these preservatives, formaldehyde has repeatedly been used unscrupulously in different foods especially in milk products. The mobile courts in their drives across Bangladesh destroyed nearly 480 liters of milk after 
detecting formalin in the two years since April, $2012 .^{6}$

Formaldehyde is a colorless, flammable gas with a pungent, suffocating odor and readily soluble in water, alcohols, diethyl ether, acetone and other polar solvents whereas formalin ( $37 \%$ solution in $\mathrm{H}_{2} \mathrm{O}$ ) is the most common solution and widely known. ${ }^{7}$ It is formed endogenously during the metabolism of amino acids and xenobiotics and most formaldehyde is probably reversibly bound to macromolecules. Owing to its reactivity with biological macromolecules, most of the formaldehyde inhaled is deposited and absorbed in regions of the upper respiratory tract with which the substance comes into first contact. ${ }^{8,9}$ It is also rapidly metabolized to formate by a number of widely distributed cellular enzymes, especially formaldehyde dehydrogenase. Owing to the rapid metabolism of formaldehyde, much of this material is eliminated in the expired air as carbon dioxide shortly after exposure. Excretion of formate in the urine is the other major route of elimination of formaldehyde. ${ }^{10,11}$

It causes vomiting, diarrhea and abdominal pain and larger doses may cause decreased body temperature, shallow respiration, weak irregular pulse and even blindness. ${ }^{12}$ It is reported to have the potential effect of significantly mis-folding DNA, RNA and native soluble proteins into insoluble fibrils comprising of cross- $ß$-sheet and oxidizing proteins with the attendant amyloid fibrillation and increase in acid levels in the blood even if it remains in the human body for only a short time. ${ }^{13}$ Inhaled formaldehyde gas is reported to have negative effects on the central nervous system, and these effects may appear in the form of insomnia, lack of concentration, memory loss, loss of appetite, and mode/balance alteration. ${ }^{14}$ Some reports have suggested that the development of bronchial asthma following inhalation of formaldehyde may be due to immunological mechanisms. ${ }^{15}$ Long term exposure to formaldehyde is known to cause irreversible neurotoxicity and is related to central nervous system cancer. ${ }^{16}$ It is considered as a known human carcinogen by many experts and government bodies, including the United States Department of Health and Human Services and the International Agency for Research on Cancer. ${ }^{17}$ Evidence of genetic effects (i.e., chromosomal aberrations, sister chromatid exchanges) in peripheral lymphocytes from individuals exposed to formaldehyde vapor has also been reported in some studies. ${ }^{18}$ So, formaldehyde should not be used in any food products and to ensure the formaldehyde free dairy products, a proper, precise and sensitive analyzing technique is necessary.

There are already few techniques/methods available for the assay of formaldehyde. But, no suitable methods have been reported to analyze formaldehyde in dairy products. However, the mobile courts in Bangladesh have been detecting formaldehyde by the instrument namely Formaldehyde Meter Z-300 (Environmental Sensors Co, USA) with limited applications to food items. ${ }^{6}$

Besides, formaldehyde can be quantitatively analyzed by spectrophotometry and fluorometry ${ }^{19}$, sol-gel based sensor ${ }^{20}$, flow-injection solid phase spectrophotometry ${ }^{21}$, HPLC ${ }^{22}$, and potentiometric sensors $^{23}$. After reviewing the articles inquisitively, we aimed to develop a RP-HPLC method to analyze formaldehyde quantitatively in the dairy products which will be easier, more sensitive, more accurate as well as time and cost effective. Therefore, our main aim was to assess formaldehyde in the marketed dairy products available in Bangladesh to check the adulteration of the food products.

\section{MATERIALS AND METHODS}

Chemicals and reagents. Analytical grade 37\% formaldehyde solution (formalin), purchased from Merck, Germany was used as working standard. HPLC grade acetonitrile (RCI Labscan, Thailand), analytical grade trichloroacetic acid (BDH Chemicals, England), sodium hydroxide pellets (Merck, India), disodium hydrogen phosphate, sodium dihydrogen phosphate (Fisher Scientific, India), DNPH (Merck, Germany), and HPLC grade water were used for analytical purposes. 
Sample collection and storage. Forty one (41) marketed dairy products were collected from departmental stores, supermarkets and farms in Dhaka, Bangladesh during mid-2013. There were 10 full cream milk, 7 milk samples from local dairy farm, 6 chocolate milk, 5 mango milk, 8 buttermilk, 2 skimmed milk, 1 banana milk, 1 flavored yoghurt and 1 yoghurt (lassi). The number of different types of collected dairy products are listed in Table 1.
Equipments. pH of each samples was checked by Cyberscan $500 \mathrm{pH}$ meter (Eutech, Singapore). The samples were processed using Kubota-2100 centrifuge machine (Kubota, Japan) and Cole-Parmer Filtration machine (USA) was used to filter the mobile phase. To analyze the samples, a binary HPLC system (Shimadzu, Japan) equipped with a vacuum degasser (Model: DGU-20A3) and a UV/Vis detector (Model: SPD-20A) was used.

Table 1. Various types of collected dairy products.

\begin{tabular}{llll}
\hline Parameters & \multicolumn{2}{c}{ Preservation technique applied } \\
\hline Products quantity & UHT-processed: 16 & Pasteurized: 9 & No preservation technique (except refrigeration): 16 \\
Source of origin & $\begin{array}{l}\text { Locally processed: } 12 \\
\text { Imported: } 4\end{array}$ & $\begin{array}{l}\text { Locally processed: } 9 \\
\text { Imported: } 0\end{array}$ & $\begin{array}{l}\text { Locally processed: } 16 \\
\text { Imported: } 0\end{array}$ \\
\hline
\end{tabular}

No product labelled the presence of preservatives especially formaldehyde in the product label claim; these samples were stored in a refrigerator below $4^{\circ} \mathrm{C}$ till further use.

Chromatographic conditions. The separation was achieved using a $5 \mu \mathrm{m}$ particle sized octadecylsilyl (ODS) column $(250 \mathrm{~mm} \times 4.6 \mathrm{~mm}$ i.d.) (Phenomenex, USA). The mobile phase consisted of acetonitrile and water at a ratio of 45:55. The mobile phase flow rate was $2.0 \mathrm{ml} / \mathrm{min}$ and the injection volume was $20 \mu \mathrm{l}$. The analyses were performed at $345 \mathrm{~nm}$ for formaldehyde.

Pre-derivatization. As formaldehyde does not possess chromophore, the RP-HPLC method required pre-column derivatization with DNPH. One $\mathrm{ml}$ of standard formaldehyde solution was mixed with 0.45 $\mathrm{ml}$ of $0.1 \%$ DNPH and shaken for $2 \mathrm{~min}$. It was then mixed with $0.4 \mathrm{ml}$ of $0.1 \mathrm{M}$ phosphate buffer $(\mathrm{pH}$ 6.8) and $1.4 \mathrm{ml}$ of $1 \mathrm{M}$ sodium hydroxide. The mixture of the solution was shaken for $1 \mathrm{~min}$ and it was then injected into HPLC after 4 min. Same procedure was followed in cases of sample solutions.

\section{Preparation of solutions}

Preparation of standard solutions. A solution of standard of known concentrations of formaldehyde (8 ppm) were prepared.

Preparation of sample solution. Accurately measured $40 \mathrm{ml}$ of marketed product was taken into a centrifuge tube with $4 \mathrm{ml}$ of trichloroacetic acid, to precipitate out the fats and proteins present in milk and milk products (41). Then it was centrifuged for $10 \mathrm{~min}$ at $3000 \mathrm{rpm}$. The supernatant was separated and then filtered using a Whatman 41 filter paper to obtain the final sample. ${ }^{24}$

\section{Validation of the test procedure}

Method validation study was performed based on the current pharmaceutical regulatory guidelines i.e., ICH Q2 (R1). A number of parameters such as precision, accuracy, specificity, linearity, ruggedness and robustness were investigated for this purpose.

System suitability. For the evaluation of system suitability, the repeatability, retention time and tailing factor of six replicates of working standard of formaldehyde (8 ppm) were used and percentage relative standard deviation (\%RSD) values were calculated in each case.

Linearity. The linearity was checked by analyzing different concentrations of formaldehyde (2 - 16 ppm). Calibration curves were made using MS Excel 2007 for each standard component. The regression line was calculated as $\mathrm{Y}=\mathrm{mX}+\mathrm{c}$, where 
$\mathrm{X}$ was the concentration of standard and $\mathrm{Y}$ was the response (peak area expressed as AU).

Limits of detection (LOD) and limits of quantitation. (LOQ). LOD and LOQ were calculated according to ICH Q2 (R1) recommendations in accordance with the $3.3 \mathrm{~s} / \mathrm{m}$ and $10 \mathrm{~s} / \mathrm{m}$ criteria respectively, where ' $\mathrm{s}$ ' is the standard deviation of the peak area and ' $m$ ' is the slope of the calibration curve determined from linearity investigation.

Accuracy (recovery test). Recovery test was done by injecting a sample of known concentration of standard solutions. Then percent recoveries (mean \pm $\%$ RSD of six replicates) were calculated.

Precision. Repeatability (intra-day precision) and intermediate precision (inter-day precision) of the methods were determined by using the solution of standard formaldehyde (8 ppm) and the solutions were analyzed in six replicates on the same day (intra-day precision) and daily for six times over a period of three days (inter-day precision).

Ruggedness. Ruggedness of the method was determined by analyzing six assay sample solutions of standard formaldehyde (8 ppm) by two analysts in the same laboratory to check the reproducibility of the result. The percentage recovery and \%RSD were calculated in both cases.
Robustness. To determine the robustness of the method, different flow rate and ratio of the mobile phase and the $\mathrm{pH}$ of the solution of sulfuric acid were introduced. The \%RSD of robustness testing under these conditions was calculated in all cases.

\section{RESULTS AND DISCUSSION}

Validation of the method

System suitability. The results (Mean \pm \%RSD of six replicates of the standards) of the parameters indicated good performance of the chromato-graphic system. The result is shown in table 2 .

Table 2. Chromatographic characteristics of system suitability.

\begin{tabular}{lll}
\hline $\begin{array}{l}\text { Peak area } \\
(\text { Mean } \pm \% R S D)\end{array}$ & $\begin{array}{l}\text { Retention time } \\
(\text { Mean } \pm \% R S D)\end{array}$ & $\begin{array}{l}\text { Tailing factor } \\
(\text { Mean } \pm \% R S D)\end{array}$ \\
\hline $216226.2 \pm 0.80$ & $15.273 \pm 0.98$ & $1.117 \pm 0.58$ \\
\hline
\end{tabular}

Linearity. The linearity was checked by analyzing 2, 4, 8, 12 and 16 ppm formaldehyde solutions. The linear regression equation for the calibration curve (figure 1) was found $\mathrm{Y}=27951 \mathrm{X}$ 5528 ( $\mathrm{X}=$ concentration and $\mathrm{Y}=$ peak area) with the correlation coefficient $\left(\mathrm{R}^{2}\right)$ of 0.999 .

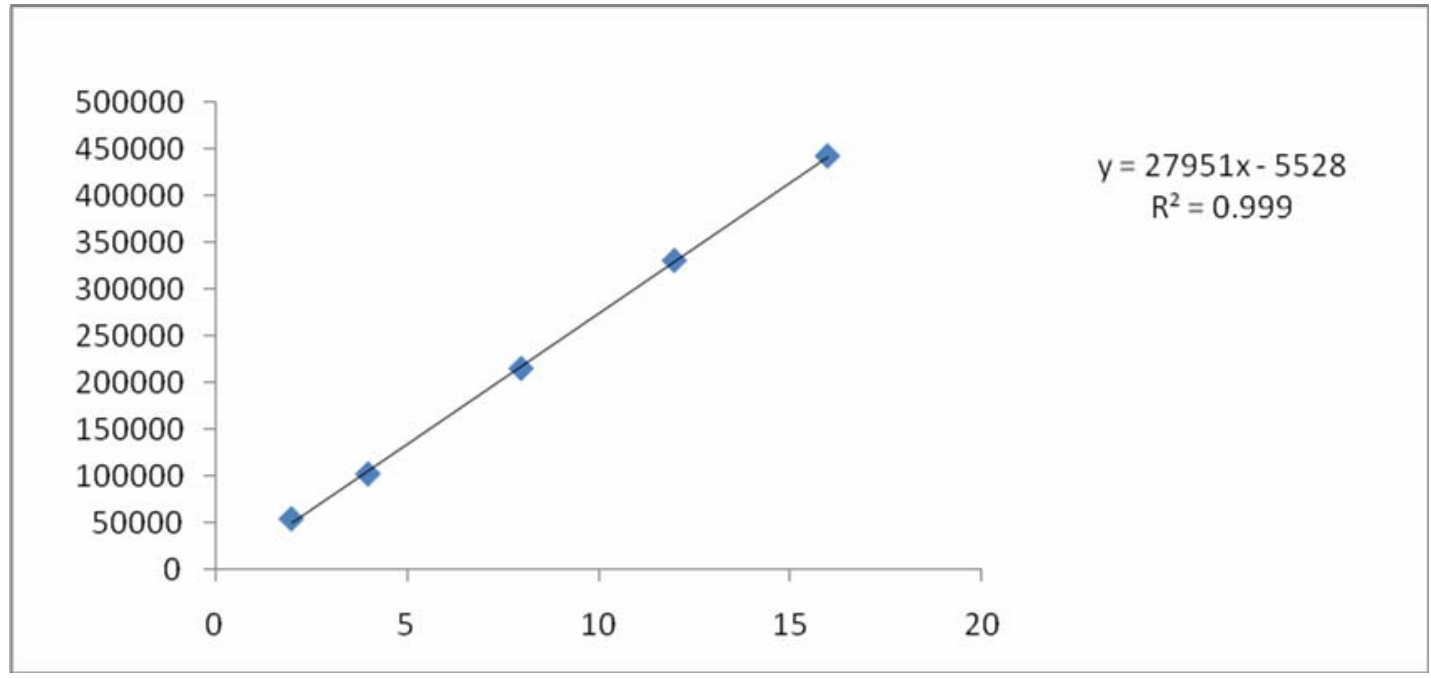

Figure 1. Calibration curve of formaldehyde. 
Limit of detection (LOD) and limit of quantitation. (LOQ). The LOD and LOQ of formaldehyde were found to be 0.4 and $1.15 \mathrm{ppm}$, respectively.

Accuracy (recovery test). The overall recoveries of the standards are summarized in table 3 . The method showed good recovery.

Precision. Repeatability (intra-day precision) and intermediate precision (inter-day precision) of the method were determined by using the solution of standard formaldehyde $(8 \mathrm{ppm})$ and the solutions were analyzed in six replicates on the same day (intra-day precision) and daily for six times over a period of three days (inter-day precision). The relevant data are shown in table 4.

Ruggedness. Ruggedness of the proposed method was determined by analyzing six assay sample solutions of standard formaldehyde (8 ppm) by two analysts in the same laboratory to check the reproducibility of the test result. The percentage recovery and standard deviation were calculated in both cases. The results (\% of recovery \pm standard deviation of six assay samples) are presented in table 5 .

Table 3. Results of accuracy determination.

\begin{tabular}{lll}
\hline $\begin{array}{l}\text { Amount used (ppm) eq. to (80\% - } \\
120 \%) \text { respectively }\end{array}$ & Amount recovered (ppm) & $\begin{array}{l}\text { \% Recovery } \\
\text { (Mean } \pm \text { RSD) }\end{array}$ \\
\hline 6.4 & 6.22 & $97.14 \pm 0.49$ \\
7.2 & 6.98 & $96.94 \pm 0.51$ \\
8 & 7.45 & $93.59 \pm 0.39$ \\
8.8 & 8.46 & $96.17 \pm 0.53$ \\
9.6 & 9.08 & $94.55 \pm 0.5$ \\
\hline
\end{tabular}

Table 4. Precision of the method.

\begin{tabular}{ccc}
\hline Spike level (\%) & Intra-day (Mean \pm \%RSD) & Inter-day (Mean \pm \%RSD) \\
\hline 100 & $216226 \pm 0.80$ & $215636 \pm 0.55$ \\
\hline
\end{tabular}

Table 5. Ruggedness study of the method.

\begin{tabular}{lccc}
\hline \multicolumn{2}{c}{ Analyst 1 } & \multicolumn{2}{c}{ Analyst 2 } \\
\hline Amount found $(\mathrm{ppm})$ & \% Recovery \pm \% RSD & Amount found (ppm) & \% Recovery \pm \% RSD \\
\hline 7.49 & $93.59 \pm 0.39$ & 7.51 & $94.26 \pm 0.51$ \\
\hline
\end{tabular}

Table 6. Robustness study of the method.

\begin{tabular}{lccc}
\hline Amount of standard $(\mathrm{ppm})$ & \multicolumn{3}{c}{ Change in flow rate } \\
\cline { 2 - 4 } & \multicolumn{4}{c}{ Amount detected $(\mathrm{ppm})($ mean \pm \%RSD) } \\
\cline { 2 - 4 } & $1.9 \mathrm{ml} / \mathrm{min}$ & $2.0 \mathrm{ml} / \mathrm{min}$ & $2.1 \mathrm{ml} / \mathrm{min}$ \\
\hline 8 & $7.78 \pm 0.99$ & \multicolumn{4}{c}{ Change of ACN : Water } \\
\cline { 2 - 4 } & \multicolumn{3}{c}{ Amount detected $(\mathrm{ppm})($ mean \pm \%RSD) } \\
\multicolumn{4}{c}{$4.75 \pm 1.04$} \\
8 & $40: 60$ & $45: 55$ & $50: 50$ \\
\hline
\end{tabular}

Robustness. The ability of method to remain unaffected by small changes in parameters is called robustness. To determine the robustness of the method, the $\mathrm{pH}$ of the solution of sulfuric acid, flow rate and different ratio of the mobile phase were introduced. The \%RSD of robustness testing under 
these conditions was calculated in all cases. Table 6 reveals the results.

Analysis of dairy products by the validated method.

A precise, accurate, robust and rugged RP-HPLC method for analysis of formaldehyde has been used $\mathrm{mV}$

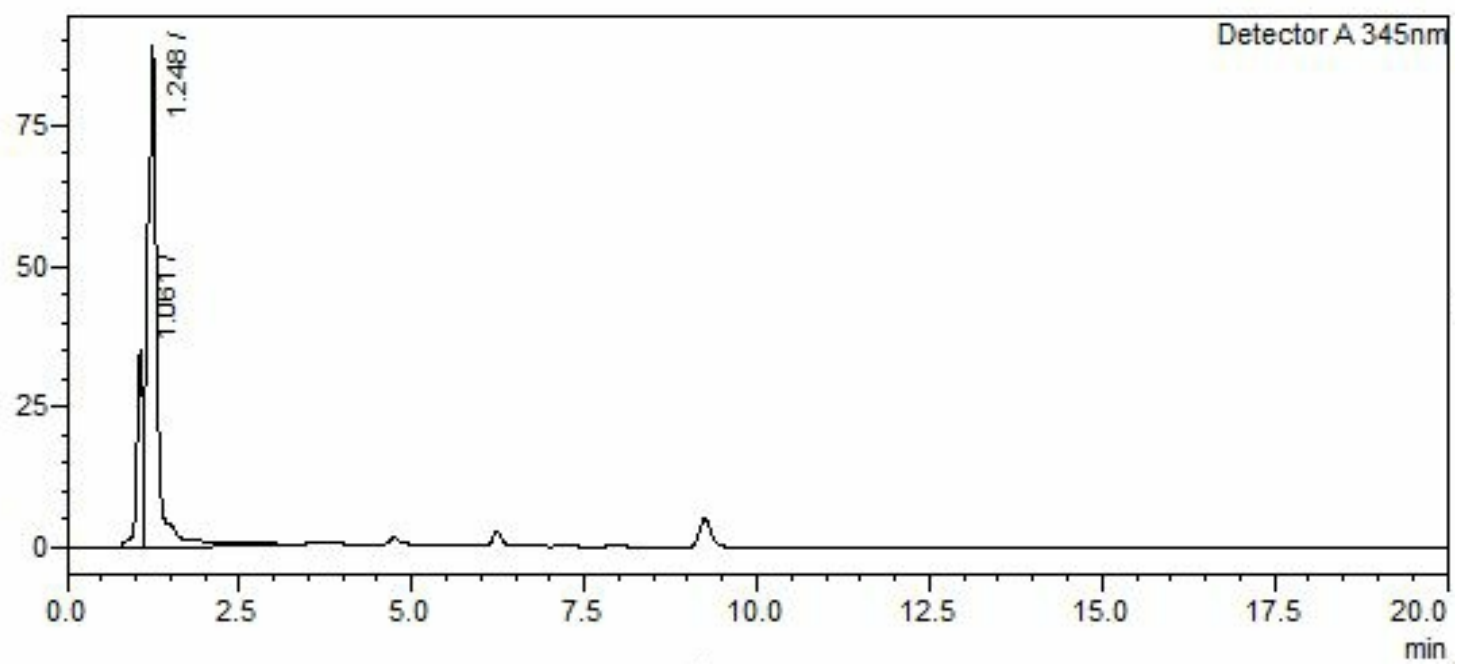

Figure 2. Chromatogram of blank.

$\mathrm{mV}$

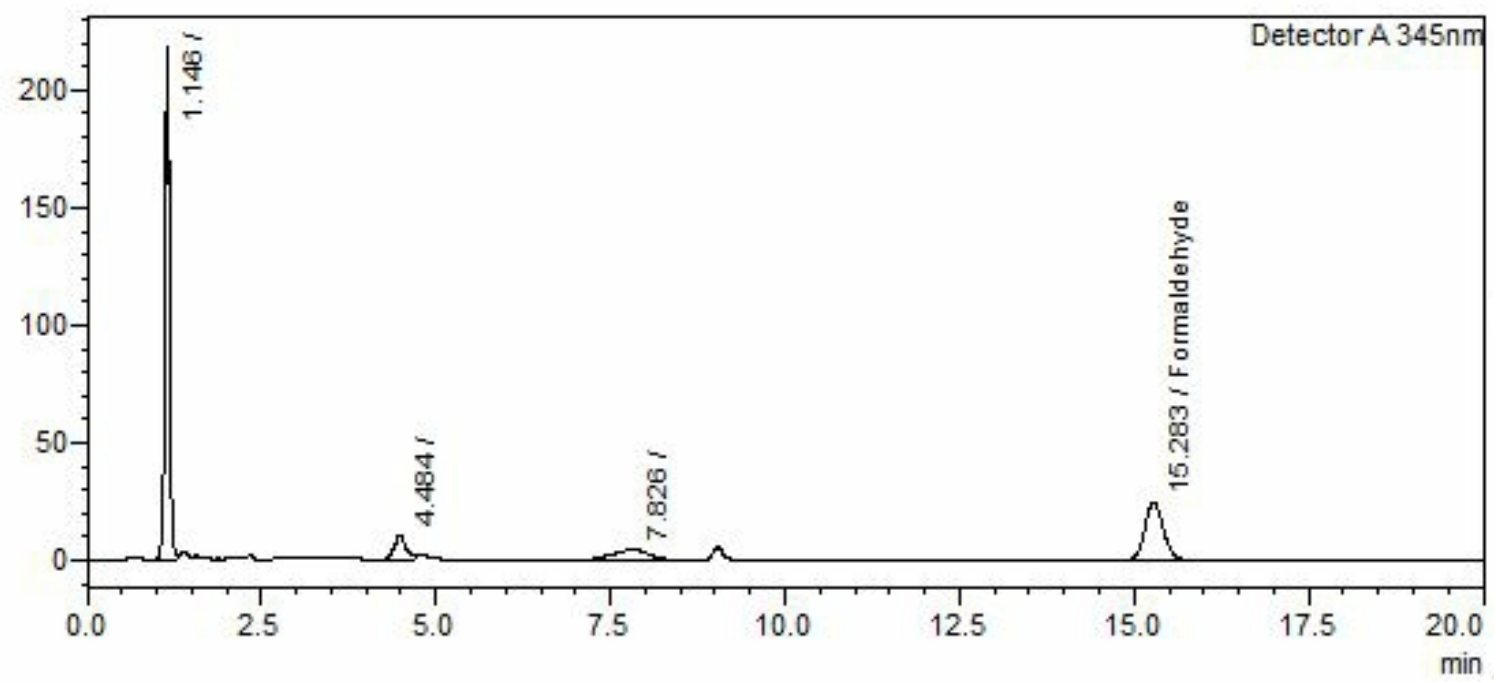

Figure 3. Chromatogram of standard formaldehyde after derivatization. to investigate 41 marketed dairy products without any difficulty within a short time. The chromatograms of blank, the standard, and a product are shown in figures 2-4, respectively. 
$\mathrm{mV}$

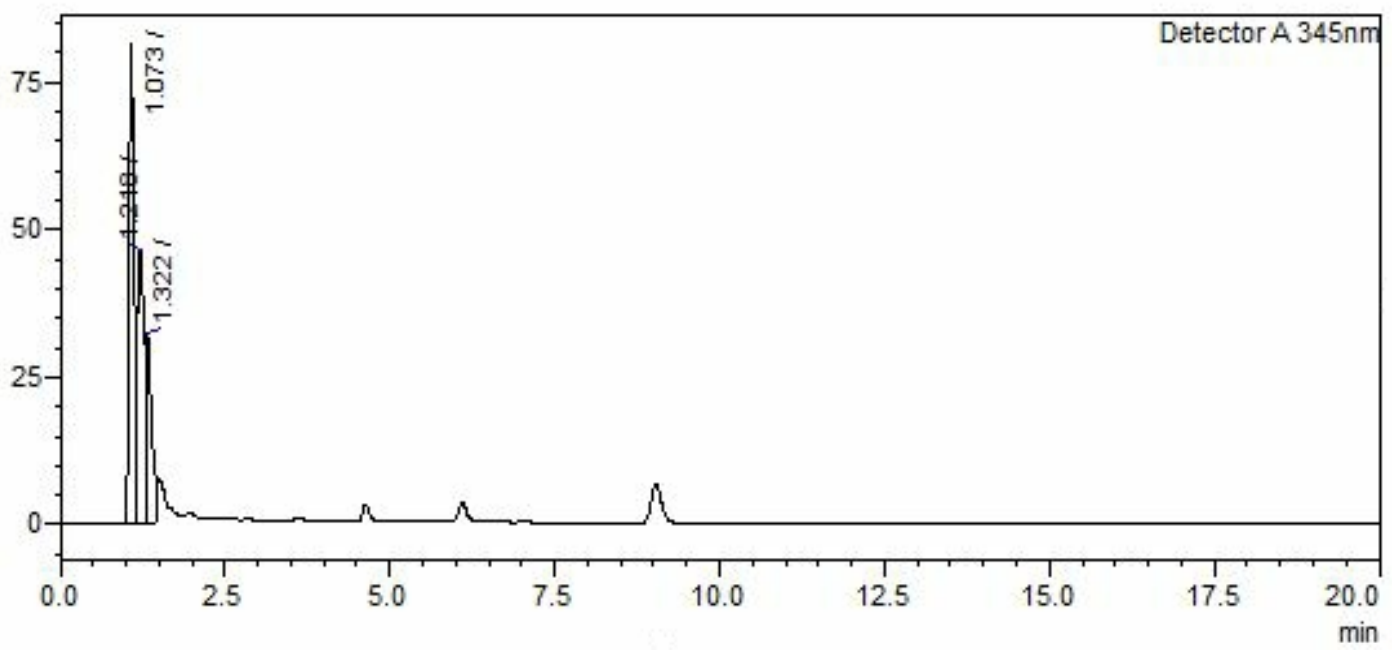

Figure 4. Chromatogram of a sample.

The method could elute formaldehyde derivative at about $15.3 \mathrm{~min}$, so the method can save time, solvents, life time of detection lamp and column. After preparing sample by a suitable way, 41 marketed dairy products were analyzed by this method to assay formaldehyde. None of the sample showed positive response to formaldehyde though it has become infamous due to its alarming use as preservative in foods. However, Chanda et. al. ${ }^{4}$ revealed that $10 \%$ of the milk samples collected from Barisal district of Bangladesh was adulterated with formaldehyde, which is contradictory to our studies. But we found formaldehyde free products due to the increasing public concern and awareness, controlled formaldehyde uses by manufacturers and effective steps taken by government agencies like 'Mobile Court Act 2009' and 'Formalin Control Act' in 2015. Further studies are needed to check the condition of dairy products in every regions of Bangladesh.

\section{CONCLUSION}

Use of formaldehyde in different food products has become a common tradition among the greedy manufacturer since the very beginning of the twenty first century. Their uses of preservatives have become major threat for human health as it causes different life threatening diseases. So, our aim was to check the marketed dairy products to verify whether they contain formaldehyde or not. We found the concentration of formaldehyde in all 41 analyzed products below the level of detection, i.e. $0.4 \mathrm{ppm}$. The obtained result is very relieving despite the current alarming situation in our food sectors. However, our suggestion is that market products investigation should be done by the concerned authorities as well as independent research groups at regular interval across the country. In such cases, the validated method can be used for the routine analysis of dairy product in food industries.

\section{ACKNOWLEDGEMENT}

This research work has been supported by Higher Education Quality Enhancement Project (HEQEP), AIF, Round-III, Window-2, CP-3245, Award No. 26, University Grants Commission (UGC), Bangladesh.

\section{REFERENCES}

1. Afzal, A., Mahmood, M.S., Hussain, I., and Akhtar, M. 2011. Adulteration and microbiological quality of milk (a review). Pak. J. Nutr. 10, 1195-1202.

2. Cempírková, R. and Mikulová, M. 2009. Incidence of psychrotrophic lipolytic bacteria in cow's raw milk. Czech $J$. Anim. Sci. 54, 65-73. 
3. Borucki, M.K., Peppin, J.D., White, D., Loge, F., and Call, D.R. 2003. Variation in biofilm formation among strains of Listeria monocytogenes. Appl. Environ. Microbiol. 69, 73367342.

4. Chanda, T., Debnath, G.K., Hossain, M.E., Islam, M.A., Begum, M.K. 2012. Adulteration of raw milk in the rural areas of Barisal district of Bangladesh. Bangladesh J. Anim. Sci. 41, 112-115.

5. Anand, S.P. and Sati, N. 2013. Artificial preservatives and their harmful effects: looking toward nature for safer alternatives. Int. J. Pharm. Sci. Res. 4, 2496-2501.

6. Palma, P. and Saha, S. 2014. Kit itself unfit at http://www.thedailystar.net/kit-itself-unfit-28852. Accessed on March 15, 2015.

7. Jayalakshmi, K., Ravikumar, H., Naidu, J., Raghavendra, R. 2011. A silent killer in the laboratory - Formaldehyde: Review of effects and management. Int. J. Oral Maxillofac. Pathol. 2, 13-19.

8. Lin, Z., Luo, W., Li, H. and Zhang, Y. 2005. The effect of endogenous formaldehyde on the rat aorta endothelial cells. Toxicol. Lett. 159, 134-143.

9. Casset, A., Marchand, C., Purohit, A., le Calve, S., UringLambert, B., Donnay, C., Meyer, P., and de Blay, F. 2006. Inhaled formaldehyde exposure: effect on bronchial response to mite allergen in sensitized asthma patients. Allergy 61, 1344-1350.

10. Thompson, C.M., Ceder, R., and Grafström, R.C. 2010. Formaldehyde dehydrogenase: beyond phase I metabolism. Toxicol. Lett. 193, 1-3.

11. Poortmans, J.R., Kumps, A., Duez, P., Fofonka, A., Carpentier, A., and Francaux, M. 2005. Effect of oral creatine supplementation on urinary methylamine, formaldehyde, and formate. Off. J. Am. Coll. Sports Med. 37, 1717-1720.

12. Gwin, M.C., G. Lienert and J. Kennedy. 2009. Formaldehyde exposure and asthma in children:a systematic review. Environ. Health Perspect. 118, 313-317.

13. Nie, C.L., Zhang, W., Zhang, D., and He, R.Q. 2005. Changes in conformation of human neuronal tau during denaturation in formaldehyde solution. Protein Pept. Lett.12, 75-78.

14. Lu, Z., Li, C.M., Qiao, Y., Yan, Y. and Yang, X. 2008. Effect of inhaled formaldehyde on learning and memory of mice. Indoor Air 18, 77-83. doi:10.1111/j.1600-0668.2008.00524.x
15. Bardana, E.J. Jr. and Montanaro, A. 1991. Formaldehyde: an analysis of its respiratory, cutaneous, and immunologic effects. Ann. Allergy 66, 441-452.

16. Kilburn, K.H. 1994. Neurobehavioral impairment and seizures from formaldehyde. Arch. Environ. Health 49, 3744.

17. Zhang, L., Steinmaus, C., Eastmond, D.A., Xin, X.K., and Smith, M.T. 2008. Formaldehyde exposure and leukemia: A new meta-analysis and potential mechanisms. Mutat. Res. doi: 10.1016/j.mrrev.2008.07.002.

18. Kitaeva, L.V., Mikheeva, E.A., Shelomova, L.F., and Shvartsman, P.Y. 1996. Genotoxic effect of formaldehyde in somatic human cells in vivo. Genetika 32, 1287-1290.

19. Li, Q., Sritharathikhun, P., and Motomizu, S. 2007. Development of novel reagent for Hantzsch reaction for the determination of formaldehyde by spectrophotometry and fluorometry. Anal. Sci. 23, 413-417.

20. Bunkoeda, O., Davisc, F., Kanatharanaa, P., Thavarungkula, P. and Higson, S.P.J. 2010. Sol-gel based sensor for selective formaldehyde determination. Anal. Chim. Acta 659, 251-257.

21. Teixeira, L.S.G., Leão, E.S., Dantas, A.F., Pinheiro, H.L.C., Costa, A.C.S., and de Andrade, J.B. 2004. Determination of formaldehyde in Brazilian alcohol fuels by flow-injection solid phase spectrophotometry. Talanta 64, 711-715.

22. Luoa, W., Lia, H., Zhanga, Y., and Ang, C.Y.W. 2001. Determination of formaldehyde in blood plasma by high performance liquid chromatography with fluorescence detection. J. Chromatogr. B: Biomed. Sci. Appl. 753, 253257.

23. Korpan, Y.I., Gonchar, M.V., Sibirny, A.A., Martelet, C., El'skaya, A.V., Gibson, T.D., and Soldatkin, A.P. 2000. Development of highly selective and stable potentiometric sensors for formaldehyde determination. Biosens. Bioelectron. 15, 77-83.

24. King, R.L. 1962.Oxidation of milk fat globule membrane material. I. Thiobarbituric acid reaction as a measure of oxidized flavor in milk and model systems. J. Dairy Sci. 45, 1165-1171. 